\title{
Assessment of Heavy Metal Bioaccumulation in Spinach, Jute Mallow and Tomato in Farms Within Kaduna Metropolis, Nigeria
}

\author{
John O. Jacob ${ }^{1, *}$, Samuel E. Kakulu ${ }^{2}$ \\ ${ }^{1}$ Federal University of Technology, PMB 65, Minna, Nigeria \\ ${ }^{2}$ University of Abuja, PMB 117, Abuja, Nigeria
}

\begin{abstract}
The heavy metals levels in soil and the edible parts of three popular vegetables, widely consumed in Nigeria; spinach (Amaranthus hybridus), jute mallow (Corchorus olitorius) and tomato (Lycopersicon esculentum) were assessed in farms within the city of Kaduna, Nigeria. The city was divided into 20 zones, for the purpose of this study, and composite samples of soils and vegetables were collected from farms and gardens in each zone and also from two rural villages, about 30 $\mathrm{km}$ from the city (as control). Samples were digested using a 3:1 mixture of concentrated $\mathrm{HNO}_{3}$ and $\mathrm{HClO}_{4}$ acids. Recovery test on method of digestion gave \% recoveries $>95 \%$ while in the analysis of reference materials of soil and plant, t-test results (at 95\% Confidence Interval) show that statistically, there exists no significant difference between certified and obtained values. Digests were analysed using Flame Atomic Absorption Spectrophotometer. The mean and range of heavy metals concentrations $(\mu \mathrm{g} / \mathrm{g}$ dry weight) in digested soil samples were $\mathrm{Pb} ; 134+94(18.2-441), \mathrm{Cd} ; 3.2+1.6(1.8-9.1), \mathrm{Ni}$; $36+40(13.5-195)$ and $\mathrm{Cr} ; 58+39(31.8-212)$, respectively, while that of vegetable samples were $\mathrm{Pb} ; 19.2+4.9(1.6-67.2)$, $\mathrm{Cd} ; 3.2+1.0(1.0-12.5), \mathrm{Ni} ; 9.6+2.5(1.6-23.1)$ and $\mathrm{Cr} ; 14.1+2.3(2.8-32.4)$,) respectively. Pollution Load Index (PLI) values indicated that the city farm soils were moderately enriched with $\mathrm{Cd}$ and $\mathrm{Cr}$, but strongly enriched with $\mathrm{Pb}$ and $\mathrm{Ni}$, due to anthropogenic contributions. The Soil-Plant Transfer Factor (TF) shows that the order of uptake of metals by vegetables is $\mathrm{Cd}>\mathrm{Ni}>\mathrm{Cr}>\mathrm{Pb}$. The mean concentrations of metals in soil samples were generally higher than the WHO/FAO maximum permissive limits in agricultural soil for $\mathrm{Pb}$ and $\mathrm{Cd}$, but lower for $\mathrm{Ni}$ and $\mathrm{Cr}$, while for vegetables the mean concentrations of metals were generally higher than the permissive limits for all the metals, except Ni. This calls for concern especially in the case of $\mathrm{Pb}$ and $\mathrm{Cd}$ which are highly toxic and of no known biological use.
\end{abstract}

Keywords Heavy Metals, Soil, Spinach, Jute, Tomato, Kaduna City

\section{Introduction}

Although trace quantities of certain heavy metals, such as chromium, cobalt, copper, manganese, zinc, e.t.c are essential micronutrients for higher animals and plant growth, they are of considerable environmental concern due to their toxicity and cumulative behavior[1]. Heavy metals are nonbiodegradable and persistent environmental contaminants, which may be deposited on the surfaces and then absorbed into the tissues of vegetables. Plants take up heavy metals by absorbing them from deposits on the parts of the plants exposed to the air from polluted environments as well as from contaminated soils[2].

As a result of urbanization and increasing anthropogenic activities, the heavy metal pollution of soil, water, and at

* Corresponding author:

jacobasol@yahoo.com (John O. Jacob)

Published online at http://journal.sapub.org/chemistry

Copyright (C) 2012 Scientific \& Academic Publishing. All Rights Reserved mosphere, represents a growing environmental problem affecting food quality and human health in cities. Sources of heavy metal in city environment include domestic and industrial wastes, traffic emissions, agricultural activities, mining and metal works[3]. Consumption of vegetables is one of the pathways by which heavy metals enter the food chain. Prolong consumption of unsafe concentrations of heavy metals through foodstuffs may lead to the chronic accumulation of heavy metals in the kidney and liver of humans causing disruption of numerous biochemical processes, leading to cardiovascular, nervous, kidney and bone diseases[4].

Urban farming is a common practice in developing countries, including Nigeria. Many residents of these urban areas are engaged in farming activities. Those who are not full-time farmers are also involved in farming to support their income. As a result of the prevailing land tenure system, land spaces for agricultural purposes are usually scarce. Urban farmers usually make use of any available land spaces that are free or the so called 'no man's land'. Such land 
usually include dumpsites, rail and road sides, and others close to market places, polluted water bodies, mechanic workshops, and industrial areas, among others, which are potential sources of heavy metal pollution.

The aim of this study was to determine the concentration of the heavy metals $\mathrm{Pb}, \mathrm{Cd}, \mathrm{Ni}$ and $\mathrm{Cr}$ (which are among the most toxic heavy metals) in soil and in the edible parts of commonly consumed vegetables of farms within Kaduna metropolis, and to evaluate the levels of bioaccumulation of the metals by the different vegetables and their risk of pollution and human health effects.

\section{Materials and Methods}

Composite samples of soils were collected from 7 - 10 farms and gardens per zone, in July 2010. Samples were collected with a stainless steel hand-trowel, within $0-20 \mathrm{~cm}$ depths. The sub-samples were collected along independent zig-zag paths to achieve randomness. The trowel was carefully cleaned after each sampling exercise, to avoid cross-contamination[5]. The soil sampling spots were cleared of debris before sampling. The soil samples were air-dried for seven days to avoid microbial degradations. Prior to analysis, the soil samples were re-dried in the oven at $110^{\circ} \mathrm{C}$ for about 3 hours and crushed in a porcelain mortar and sieved through a $2 \mathrm{~mm}$ plastic sieve to obtain fine soil particles. $1 \mathrm{~g}$ of the oven-dried $(<2 \mathrm{~mm})$ composite soil sample from each of the 22 zones (in triplicates) were first moistened with a few drops of water (to prevent sputtering) followed by the addition of $10 \mathrm{~cm}^{3}$ concentrated nitric acid $\left(\mathrm{HNO}_{3}\right)$. The mixture was slowly evaporated over a period of 1 hour, on a hot plate. The solid residue obtained was digested with $20 \mathrm{~cm}^{3}$ of a $3: 1$ mixture of concentrated $\mathrm{HNO}_{3}$ and $\mathrm{HClO}_{4}$ for ten minutes at room temperature before heating was continued. The temperature of the hot plate was slowly raised over a period of 1 hour until the fumes of $\mathrm{HClO}_{4}$ starts to escape, heating was continued until a clear solution was obtained. The mixture was allowed to cool to room temperature. The cooled mixture was then filtered using Whatman No. 1 filter paper into $100 \mathrm{~cm}^{3}$ volumetric flask and made up to mark with distilled water. The digests were stored in polythene bottles till analysis[6].

Vegetable samples were collected with gloved hands to avoid contamination. Samples of spinach (Amaranthus hybridus) and jute mallow (Corchorus olitorius) were collected by randomly picking up some mature bottom leaves from the matured plants until a sizable bundle was gathered from each farm or garden where soil samples were taken. Ripe fruits of tomato (Lycopersicon esculentum) were collected by randomly plucking the fruits from the plants[5]. On reaching the laboratory, for each type of vegetables, collections from each zone were washed with distilled water to remove dirt and other particulate matters. Each collection or bundles were then sub-divided to give triplicate samples weighing approximately $100 \mathrm{~g}$ fresh weight. Prior to analysis, fresh vegetable samples were dried in the oven at $70^{\circ} \mathrm{C}$ until a constant weight was obtained. Samples were then pulverized using a porcelain mortar, sieved through $1 \mathrm{~mm}$ mesh sieve, and stored in polythene bags ready for digestion and analysis. $1 \mathrm{~g}$ of oven-dried and ground sample of each type of vegetable and from each of the 22 zones were weighed (in triplicates) into a $50 \mathrm{~cm}^{3}$ beaker. This was followed by the addition of $10 \mathrm{~cm}^{3}$ mixtures of analytical grade acids $\mathrm{HNO}_{3}$ and $\mathrm{HClO}_{4}$ in the ratio 3:1. The beakers were then covered with watch glasses and left overnight. Digestion was done on a hot plate at a temperature of about $90^{\circ} \mathrm{C}$ in a fume cupboard until about $4 \mathrm{~cm}^{3}$ of the mixture was left in the beaker. A further $10 \mathrm{~cm}^{3}$ of the acid mixture was then added and evaporated to a volume of about $4 \mathrm{~cm}^{3}$ while still on hot plate, giving a clear solution. The mixture was cooled to room temperature and the solution filtered using Whatman No. 1 filter paper, to remove small quantities of waxy solids and made up to a final volume of $50 \mathrm{~cm}^{3}$ with distilled water in a volumetric flask. These were stored in polythene bottles till analysis[1].

In order to confirm the efficiency of the $\mathrm{HNO}_{3}-\mathrm{HClO}_{4}$ method of sample digestion a recovery study was carried out by spiking $1 \mathrm{~g}$ of five different soil samples each with $1 \mathrm{~cm}^{3}$ of standard solutions of the metals $\mathrm{Pb}, \mathrm{Cd}, \mathrm{Ni}$ and $\mathrm{Cr}$. Furthermore, reference samples of soil and plant were analyzed, under similar conditions. Recovery test gave \% recoveries > $95 \%$ while in the analysis of reference materials t-test results (at 95\% Confidence Interval) show that statistically, there exists no significant difference between certified and obtained values.

Metal concentrations in working standards and digests were determined using Flame Atomic Absorption Spectrophotometer (Perkin Elmer A-ANALYST 200). Air- acetylene flame was used. The instrumental settings and operating conditions were carried out according to the manufacturer's specifications. Blanks were also determined to ascertain the contribution of reagents to metal levels.

\section{Results and Discussion}

The mean concentrations of the heavy metals $(\mu \mathrm{g} / \mathrm{g}$ dry weight) in soil, spinach, jute and tomato are given in Tables 1, $3,5 \& 6$ respectively. The concentrations of the metals were generally higher in samples from the study site than the control site. Pollution Load Index values (Table 2) shows that the city farm soils were moderately enriched with $\mathrm{Cd}$ and $\mathrm{Cr}$, but strongly enriched with $\mathrm{Pb}$ and $\mathrm{Ni}$, due to anthropogenic contributions. The order of accumulation of metals in both soil and vegetables samples was $\mathrm{Pb}>\mathrm{Cr}>$ $\mathrm{Ni}>\mathrm{Cd}$. Plants generally have low uptake of $\mathrm{Pb}$, high concentration of $\mathrm{Pb}$ in vegetables in this study could be attributed to its high concentration in soil and possible aerial deposition and absorption.

The high concentrations of $\mathrm{Pb}$ and $\mathrm{Cr}$ in soil samples could be attributed to high level of industrial activities, metal works, vehicular emissions, small scale tanning operations, e.t.c. The distribution of metals in farm soils in each zone 
was mainly affected by the location of the zone and the prevailing anthropogenic activities. Spinach accumulated more metals, followed by jute mallow and then tomato. This is in agreement with some earlier reports that leafy vegetables have greater potential for accumulating heavy metals in their edible parts than grains and fruit crops, due to their higher transpiration rate[5]. It is essential to note also that spinach has broader leaves than jute mallow, while tomato is a fruit vegetable. There existed strong correlation between concentrations of metals in soil. These correlations were statistically significant $(\mathrm{p}<0.05)$, indicating similar sources of pollution[7]. In addition positive correlation indicates mutual existence and enrichment of the metals in soil, whereas negative correlation indicates their competition to occupy the same sites in soil exchange base or lattice. However, other factors for significant correlation of the metals in soil are similar atomic radii for $\mathrm{Cd}, \mathrm{Cr}$ and similar chemical and physical factors controlling element association in parent material and during soil forming processes[8]. This result is consistent with previously published data[9]. The general weak correlation between concentrations of metals in soil and in vegetables, which had also been reported[10], indicates that other sources, such as foliar absorption, might have contributed to the metal burden in vegetables.

Table 1. Mean Concentration ( $\mu \mathrm{g} / \mathrm{g}$ dry weight) of Heavy Metals in Soil Samples

\begin{tabular}{|c|c|c|c|c|}
\hline Zone & $\mathrm{Pb}$ & $\mathrm{Cd}$ & $\mathrm{Ni}$ & $\mathrm{Cr}$ \\
\hline 1 & $67.8 \pm 0.4$ & $3.0 \pm 0.4$ & $19.6 \pm 4.6$ & $53.2 \pm 0.8$ \\
\hline 2 & $190 \pm 24$ & $2.5 \pm 0.1$ & $31.7 \pm 0.2$ & $56.9 \pm 4.5$ \\
\hline 3 & $256 \pm 44$ & $2.5 \pm 1.6$ & $15.8 \pm 0.8$ & $56.5 \pm 9.8$ \\
\hline 4 & $425 \pm 77$ & $6.2 \pm 0.4$ & $38.4 \pm 6.5$ & $43.9 \pm 9.9$ \\
\hline 5 & $327 \pm 14$ & $7.7 \pm 0.4$ & $46.8 \pm 0.6$ & $64.7 \pm 7.6$ \\
\hline 6 & $43.5 \pm 0.2$ & $1.8 \pm 0.3$ & $22.1 \pm 0.1$ & $42.7 \pm 7.1$ \\
\hline 7 & $32.1 \pm 7.4$ & $2.3 \pm 0.1$ & $30.6 \pm 0.2$ & $51.4 \pm 0.2$ \\
\hline 8 & $256 \pm 8$ & $3.8 \pm 0.2$ & $27.4 \pm 1.3$ & $42.1 \pm 2.5$ \\
\hline 9 & $99.4 \pm 2.3$ & $2.2 \pm 0.1$ & $26.4 \pm 2.8$ & $40.4 \pm 6.5$ \\
\hline 10 & $35.9 \pm 6.7$ & $2.3 \pm 0.9$ & $20.8 \pm 2.8$ & $31.8 \pm 1.1$ \\
\hline 11 & $18.2 \pm 3.1$ & $2.1 \pm 0.1$ & $13.5 \pm 1.9$ & $34.4 \pm 2.8$ \\
\hline 12 & $48.6 \pm 7.6$ & $3.9 \pm 1.1$ & $28.5 \pm 3.1$ & $51.5 \pm 6.9$ \\
\hline 13 & $28.0 \pm 1.4$ & $1.9 \pm 0.2$ & $22.8 \pm 1.7$ & $40.5 \pm 0.9$ \\
\hline 14 & $25.2 \pm 0.2$ & $1.9 \pm 0.3$ & $30.2 \pm 0.4$ & $54.7 \pm 5.3$ \\
\hline 15 & $441 \pm 42$ & $9.1 \pm 0.5$ & $195 \pm 8.3$ & $212 \pm 11$ \\
\hline 16 & $104 \pm 10$ & $2.5 \pm 0.4$ & $28.1 \pm 3.1$ & $58.9 \pm 7.4$ \\
\hline 17 & $74 \pm 16$ & $2.3 \pm 0.5$ & $25.2 \pm 2.1$ & $54.7 \pm 3.6$ \\
\hline 18 & $144 \pm 29$ & $2.3 \pm 0.4$ & $52.9 \pm 3.5$ & $70.1 \pm 3.9$ \\
\hline 19 & $22.3 \pm 2.5$ & $1.8 \pm 0.1$ & $13.5 \pm 0.7$ & $51.9 \pm 7.1$ \\
\hline 20 & $48.7 \pm 2.7$ & $2.8 \pm 0.5$ & $25.4 \pm 3.1$ & $45.8 \pm 4.2$ \\
\hline $21^{\mathrm{c}}$ & $17.9 \pm 2.6$ & $1.2 \pm 0.1$ & $4.1 \pm 1.2$ & $13.7 \pm 2.2$ \\
\hline $22^{\mathrm{c}}$ & $11.4 \pm 1.1$ & $1.3 \pm 0.3$ & $2.5 \pm 1.3$ & $17.6 \pm 2.5$ \\
\hline
\end{tabular}

$\mathrm{c}=$ control

The Soil-Plant Transfer Factor (TF) differed between the vegetables species and sampling zones (Table 4). The difference in sampling zones for the same vegetable could be attributed to differences in soil properties[11]. The TF values showed that the order of uptake of metals by vegetables is $\mathrm{Cd}>\mathrm{Ni}>\mathrm{Cr}>\mathrm{Pb}$. Cd had the highest $\mathrm{TF}$ in all the vegetables. This is due to its high mobility[7]. The trend is in consistent with the result obtained by Khan, et al[12]; with $\mathrm{Cd}$ having the highest $\mathrm{TF}$ and $\mathrm{Cr}$ and $\mathrm{Pb}$ the lowest. Spinach generally had the highest TF for all metals followed by jute mallow; this could be attributed to their relative transpiration rate[13].

Table 2. Pollution Load Index (PLI*) of Study Site

\begin{tabular}{|c|c|c|c|c|}
\hline & $\mathrm{Pb}$ & $\mathrm{Cd}$ & $\mathrm{Ni}$ & $\mathrm{Cr}$ \\
\hline Soil & 9.14 & 2.46 & 10.82 & 3.69 \\
\hline Spinach & 2.00 & 2.29 & 1.71 & 1.94 \\
\hline Jute Mallow & 3.45 & 2.19 & 5.13 & 4.40 \\
\hline Tomato & 4.24 & 1.53 & 5.70 & 4.94 \\
\hline
\end{tabular}

* PLI $=$ [Concentration of metal in study site/Concentration in control site $]$

Table 3. Mean Concentration ( $\mu \mathrm{g} / \mathrm{g}$ dry weight) of Heavy Metals in Spinach Samples

\begin{tabular}{|c|c|c|c|c|}
\hline Zone & $\mathrm{Pb}$ & $\mathrm{Cd}$ & $\mathrm{Ni}$ & $\mathrm{Cr}$ \\
\hline 1 & $11.7 \pm 3.8$ & $4.5 \pm 2.1$ & $17.2 \pm 1.5$ & $20.4 \pm 2.9$ \\
\hline 2 & $27.2 \pm 4.5$ & $5.1 \pm 1.3$ & $12.7 \pm 4.1$ & $18.8 \pm 1.1$ \\
\hline 3 & $14.5 \pm 4.1$ & $3.4 \pm 0.3$ & $16.3 \pm 1.6$ & $10.4 \pm 1.7$ \\
\hline 4 & $3.4 \pm 2.4$ & $3.9 \pm 1.8$ & $19.8 \pm 2.3$ & $12.5 \pm 1.3$ \\
\hline 5 & $26.2 \pm 4.5$ & $2.9 \pm 0.4$ & $11.6 \pm 2.9$ & $12.4 \pm 2.6$ \\
\hline 6 & $18.1 \pm 3.9$ & $5.1 \pm 1.7$ & $14.4 \pm 1.3$ & $7.6 \pm 1.3$ \\
\hline 7 & $1.9 \pm 0.7$ & $4.5 \pm 2.8$ & $16.7 \pm 2.7$ & $8.4 \pm 0.2$ \\
\hline 8 & $11.6 \pm 1.8$ & $3.9 \pm 1.3$ & $13.4 \pm 2.2$ & $27.9 \pm 2.4$ \\
\hline 9 & $4.3 \pm 1.7$ & $1.0 \pm 0.1$ & $8.7 \pm 1.5$ & $12.6 \pm 0.7$ \\
\hline 10 & $22.1 \pm 2.8$ & $4.3 \pm 1.3$ & $12.5 \pm 1.1$ & $9.9 \pm 2.1$ \\
\hline 11 & $8.5 \pm 2.2$ & $3.6 \pm 1.9$ & $12.7 \pm 3.3$ & $11.9 \pm 1.4$ \\
\hline 12 & $11.0 \pm 1.9$ & $6.6 \pm 0.9$ & $23.1 \pm 5.1$ & $28.9 \pm 5.7$ \\
\hline 13 & $12.5 \pm 3.9$ & $2.6 \pm 1.4$ & $14.4 \pm 2.8$ & $18.9 \pm 2.1$ \\
\hline 14 & $1.6 \pm 1.1$ & $4.2 \pm 1.9$ & $18.9 \pm 1.2$ & $11.2 \pm 2.5$ \\
\hline 15 & $12.7 \pm 2.6$ & $3.5 \pm 1.7$ & $14.2 \pm 5.2$ & $15.1 \pm 1.5$ \\
\hline 16 & $12.4 \pm 3.2$ & $3.1 \pm 1.3$ & $16.8 \pm 4.2$ & $24.7 \pm 0.9$ \\
\hline 17 & $11.9 \pm 1.6$ & $3.2 \pm 1.2$ & $15.7 \pm 3.7$ & $17.5 \pm 1.3$ \\
\hline 18 & $28.3 \pm 5.6$ & $1.7 \pm 1.1$ & $8.7 \pm 2.3$ & $25.2 \pm 0.8$ \\
\hline 19 & $4.7 \pm 2.6$ & $3.9 \pm 1.4$ & $12.9 \pm 2.3$ & $9.7 \pm 1.7$ \\
\hline 20 & $14.7 \pm 1.1$ & $6.6 \pm 1.7$ & $17.6 \pm 3.4$ & $26.1 \pm 1.1$ \\
\hline $21^{\mathrm{c}}$ & $5.8 \pm 1.9$ & $1.5 \pm 0.7$ & $7.7 \pm 1.3$ & $7.7 \pm 3.1$ \\
\hline $22^{\mathrm{c}}$ & $7.1 \pm 3.1$ & $1.8 \pm 0.3$ & $9.6 \pm 2.1$ & $9.2 \pm 2.8$ \\
\hline
\end{tabular}

$\mathrm{c}=$ control

Table 4. Mean Soil-Plant Transfer Factor (TF) of Vegetables

\begin{tabular}{|c|c|c|c|c|}
\hline & $\mathrm{TF}_{\mathrm{Pb}}$ & $\mathrm{TF}_{\mathrm{Cd}}$ & $\mathrm{TF}_{\mathrm{Ni}}$ & $\mathrm{TF}_{\mathrm{Cr}}$ \\
\hline Spinach & $0.19 \pm 0.14 \mathrm{a}$ & $1.47 \pm 0.54$ & $0.59 \pm 0.21$ & $0.33 \pm 0.13$ \\
\hline Jute Mallow & $0.40+0.53$ & $1.4 \pm 1.1$ & $0.32 \pm 0.16$ & $0.34 \pm 0.20$ \\
\hline Tomato & $0.14 \pm 0.11$ & $0.87 \pm 0.24$ & $0.22 \pm 0.12$ & $0.19 \pm 0.06$ \\
\hline Mean & 0.24 & 1.25 & 0.38 & 0.29 \\
\hline
\end{tabular}

Table 5. Mean Concentration ( $\mu \mathrm{g} / \mathrm{g}$ dry weight) of Heavy Metals in Jute Mallow Samples

\begin{tabular}{|c|c|c|c|c|}
\hline Zone & $\mathrm{Pb}$ & $\mathrm{Cd}$ & $\mathrm{Ni}$ & $\mathrm{Cr}$ \\
\hline 1 & $8.7 \pm 3.8$ & $4.6 \pm 1.7$ & $7.8 \pm 3.1$ & $22.6 \pm 3.8$ \\
\hline 2 & $7.8 \pm 1.1$ & $4.5 \pm 2.1$ & $11.8 \pm 5.9$ & $32.4 \pm 2.7$ \\
\hline 3 & $5.8 \pm 2.3$ & $2.9 \pm 0.6$ & $7.9 \pm 3.2$ & $9.8 \pm 3.4$ \\
\hline 4 & $5.1 \pm 3.3$ & $2.6 \pm 0.5$ & $7.2 \pm 3.9$ & $9.7 \pm 2.4$ \\
\hline 5 & $42.9 \pm 3.5$ & $1.9 \pm 0.6$ & $13.5 \pm 3.6$ & $26.9 \pm 1.8$ \\
\hline 6 & $17.3 \pm 1.6$ & $2.8 \pm 1.1$ & $6.7 \pm 1.6$ & $10.9 \pm 3.8$ \\
\hline 7 & $19.2 \pm 3.3$ & $2.5 \pm 1.4$ & $12.3 \pm 1.4$ & $23.7 \pm 2.5$ \\
\hline 8 & $16.6 \pm 2.1$ & $3.3 \pm 1.1$ & $5.7 \pm 1.4$ & $17.8 \pm 2.9$ \\
\hline 9 & $5.1 \pm 1.48$ & $1.2 \pm 0.2$ & $1.9 \pm 0.6$ & $9.2 \pm 1.4$ \\
\hline 10 & $10.8 \pm 1.8$ & $2.2 \pm 0.9$ & $6.2 \pm 3.5$ & $30.8 \pm 4.7$ \\
\hline 11 & $26.4 \pm 3.6$ & $3.7 \pm 1.1$ & $9.9 \pm 0.6$ & $8.4 \pm 1.6$ \\
\hline 12 & $12.9 \pm 3.4$ & $2.5 \pm 0.1$ & $16.5 \pm 1.7$ & $11.5 \pm 2.4$ \\
\hline 13 & $67.2 \pm 1.4$ & $4.7 \pm 1.2$ & $14.1 \pm 4.8$ & $14.4 \pm 3.5$ \\
\hline 14 & $18.2 \pm 4.9$ & $3.1 \pm 0.4$ & $7.1 \pm 1.4$ & $16.9 \pm 2.6$ \\
\hline 15 & $4.2 \pm 1.7$ & $2.8 \pm 0.1$ & $4.4 \pm 1.4$ & $10.7 \pm 2.9$ \\
\hline 16 & $16.8 \pm 1.8$ & $12.5 \pm 2.1$ & $12.8 \pm 1.3$ & $29.8 \pm 4.9$ \\
\hline 17 & $10.4 \pm 1.7$ & $2.3 \pm 0.1$ & $1.6 \pm 0.2$ & $12.8 \pm 4.2$ \\
\hline 18 & $8.3 \pm 1.4$ & $2.8 \pm 0.2$ & $4.2 \pm 1.6$ & $16.6 \pm 2.8$ \\
\hline 19 & $16.2 \pm 2.7$ & $3.7 \pm 0.7$ & $6.1 \pm 1.4$ & $13.3 \pm 1.7$ \\
\hline 20 & $17.2 \pm 3.2$ & $3.6 \pm 1.2$ & $5.4 \pm 1.9$ & $15.5 \pm 1.5$ \\
\hline $21^{\mathrm{c}}$ & $3.3 \pm 0.6$ & $1.4 \pm 0.4$ & $1.9 \pm 0.4$ & $2.1 \pm 0.7$ \\
\hline $22^{\mathrm{c}}$ & $6.6 \pm 2.8$ & $1.7 \pm 0.7$ & $1.2 \pm 0.3$ & $5.6 \pm 1.4$ \\
\hline
\end{tabular}

$\mathrm{c}=$ control 
Table 6. Mean Concentration ( $\mu \mathrm{g} / \mathrm{g}$ dry weight) of Heavy Metals in Tomato Samples

\begin{tabular}{|c|c|c|c|c|}
\hline Zone & $\mathrm{Pb}$ & $\mathrm{Cd}$ & $\mathrm{Ni}$ & $\mathrm{Cr}$ \\
\hline 1 & $7.9 \pm 0.4$ & $2.5 \pm 0.2$ & $4.6 \pm 1.3$ & $3.8 \pm 0.7$ \\
\hline 2 & $9.4 \pm 1.4$ & $2.1 \pm 0.1$ & $4.6 \pm 1.7$ & $4.2 \pm 0.1$ \\
\hline 3 & $9.6 \pm 4.2$ & $3.2 \pm 1.1$ & $4.4 \pm 0.4$ & $9.7 \pm 2.3$ \\
\hline 4 & $13.3 \pm 1.7$ & $2.4 \pm 0.7$ & $2.4 \pm 0.9$ & $10.9 \pm 1.1$ \\
\hline 5 & $9.7 \pm 1.1$ & $1.8 \pm 0.2$ & $4.8 \pm 0.2$ & $10.1 \pm 1.6$ \\
\hline 6 & $10.2 \pm 2.8$ & $1.9 \pm 0.5$ & $5.5 \pm 0.4$ & $9.9 \pm 1.1$ \\
\hline 7 & $5.3 \pm 1.9$ & $2.1 \pm 0.4$ & $3.4 \pm 0.4$ & $9.3 \pm 1.8$ \\
\hline 8 & $5.1 \pm 1.4$ & $2.2 \pm 0.7$ & $4.6 \pm 1.5$ & $9.7 \pm 0.9$ \\
\hline 9 & $29.6 \pm 3.3$ & $2.1 \pm 0.3$ & $5.7 \pm 2.1$ & $13.6 \pm 5.2$ \\
\hline 10 & $4.7 \pm 1.4$ & $1.8 \pm 0.2$ & $12.2 \pm 0.9$ & $3.4 \pm 0.7$ \\
\hline 11 & $3.9 \pm 0.2$ & $2.5 \pm 0.6$ & $2.5 \pm 0.3$ & $17.1 \pm 1.3$ \\
\hline 12 & $23.6 \pm 2.7$ & $2.4 \pm 0.7$ & $9.7 \pm 0.3$ & $11.9 \pm 4.8$ \\
\hline 13 & $7.2 \pm 2.3$ & $2.5 \pm 0.8$ & $11.5 \pm 2.1$ & $6.6 \pm 3.1$ \\
\hline 14 & $5.4 \pm 2.7$ & $2.3 \pm 0.4$ & $3.4 \pm 0.7$ & $5.6 \pm 0.6$ \\
\hline 15 & $5.1 \pm 0.7$ & $2.1 \pm 0.3$ & $5.6 \pm 1.6$ & $7.7 \pm 1.7$ \\
\hline 16 & $4.2 \pm 1.3$ & $2.1 \pm 0.6$ & $4.2 \pm 1.7$ & $2.8 \pm 0.1$ \\
\hline 17 & $5.9 \pm 2.1$ & $2.3 \pm 0.4$ & $4.2 \pm 1.4$ & $5.7 \pm 0.1$ \\
\hline 18 & $8.3 \pm 1.3$ & $2.1 \pm 1.1$ & $12.1 \pm 1.4$ & $16.8 \pm 0.1$ \\
\hline 19 & $6.1 \pm 1.7$ & $2.2 \pm 0.6$ & $4.2 \pm 1.5$ & $4.8 \pm 0.4$ \\
\hline 20 & $4.4 \pm 0.9$ & $2.6 \pm 0.7$ & $4.1 \pm 0.3$ & $5.3 \pm 0.6$ \\
\hline $21^{\mathrm{c}}$ & $2.9 \pm 0.2$ & $1.7 \pm 0.2$ & $0.5 \pm 0.1$ & $1.6 \pm 0.1$ \\
\hline $22^{\mathrm{c}}$ & $1.2 \pm 0.6$ & $1.2 \pm 0.3$ & $1.4 \pm 0.3$ & $1.8 \pm 0.1$ \\
\hline
\end{tabular}

$\mathrm{c}=$ control

\section{Conclusions}

The concentrations of $\mathrm{Pb}$ and $\mathrm{Cd}$ in the soil samples were generally higher than the $\mathrm{WHO} / \mathrm{FAO}$ maximum permissive limits while the concentrations of $\mathrm{Ni}, \mathrm{Cr}$, in soil samples were generally lower than the maximum permissive limits $(\mathrm{Pb} 100 ; \mathrm{Cd} \mathrm{3}$; Ni 75; Cr $400 \mu \mathrm{g} / \mathrm{g})[14]$, except for few zones. On the other hand, in vegetables, the concentrations of $\mathrm{Pb}, \mathrm{Cd}$ and $\mathrm{Cr}$ (in all zones) were higher than the WHO/FAO maximum permissive limits ( $\mathrm{Pb} \mathrm{0.3;} \mathrm{Cd} \mathrm{0.2;} \mathrm{Ni} \mathrm{10;} \mathrm{Cr} 2.3$ $\mu \mathrm{g} / \mathrm{g}$ )[14], while $\mathrm{Ni}$ concentration was higher than the maximum permissive limit in spinach samples only. Furthermore, the study revealed that some areas of the city were more polluted by a particular metal than the other due to the prevailing anthropogenic activities in the area, and that all areas of the city run the risk of pollution by $\mathrm{Pb}, \mathrm{Cd}$ and $\mathrm{Cr}$ in vegetables. There was generally no critical $\mathrm{Ni}$ contamination of the vegetables.

\section{REFERENCES}

[1] Yusuf, A. A., Arowolo, T. O. and Bamgbose, O., 2002, “Cadmium, Copper and Nickel levels in vegetables from industrial and residentialareas of Lagos city, Nigeria", Global Journal of Environ Science, 1(1), $1-6$

[2] Kachenko, A. G. and Singh, B., 2006, "Heavy metals contamination in vegetables grown in urban and metal smelter contaminated sites in Australia", Water, Air and Soil Pollution, $169,101-123$

[3] Nriagu, J. O., 1990, “Global metal pollution", Environment, 32(7), $7-33$

[4] Sharma, R. J., Agrawal, M. and Marshall, F. M., 2009, "Heavy metals in vegetables collected from production and market sites of a tropical urban area of Indian", Food and Chemical Technology, 47, 583 - 591

[5] Mapanda, F., Mangwayana, E. N, Nyamangara, J. Giller, K. E., 2007, "Uptake of heavy metals by vegetables irrigated using wastewater and the subsequent risks in Harare", Phys ics and Chemistry of the Earth, 32, 1399 - 1405

[6] Fatoki, O. S., 1996, "Trace Zinc and Copper concentration in roadside surface soils and vegetation - measurement of local atmospheric pollution in Alice, South Africa, Environ ment International, 22(6), $759-762$

[7] M. N. V. Prasad, "Heavy Metal Stress in Plants", Second Edition, Springer, U. K., 2004, p. $484-487$

[8] A. Kabata - Pendias, and A. Pendias, "Trace Elements in Soils and Plants", Third Edition, CRC Press, 2001, p.2 - 5.

[9] Ma, L. Q. and Rao, G. N., 1997, "Chemical fractionation of Cadmium, Copper, Nickel and Zinc in contaminated soils", Journal of Environmental Quality, 26(1), 259 - 264

[10] Agbenin, J. O., Danko, M. and Welp, G. (2009): "Soil and vegetable compositional relationships of eight potentially toxic metals in urban garden fields from Northern Nigeria", Journal of the Science of Food and Agriculture, 89, 49 - 54

[11] Kanakaraju, D., Mazura, N. A. and Khairulanwar, A., 2007, "Relationship between metals in vegetables with soils in farmlands of Kuching, Sarawak", Malaysian Journal of Soil Science, $11,57-69$

[12] Khan, S. Cao, Q., Zheng, Y. M., Huang, Y. Z. and Zhu, Y. G., 2008 , "Health risks of heavy metals in contaminated soils and food crops irrigated with wastewater in Beijing, China", Environmental Pollution, 152, 686-692

[13] Kisku, G. C., Barman, S. C., Bhargava, S. K., 2000, "Contamination of soil and plant with potentially toxic elements irrigated with mixed industrial effluent and its impact on the environment", Water, Air, Soil Pollution, 120, 121 - 137

[14] WHO/FAO: Codex Alimentarius Commission, "Food Additives and Contaminants", Joint FAO/WHO Food Stan dards Programme, 2001; ALINORM 01/12A: 1 - 289 